\title{
«Un espíritu nuevo»: la cuestión social y el Derecho en la Argentina (1890-1930)
}

\author{
por \\ Eduardo Zimmermann \\ Universidad de San Andrés - Buenos Aires
}

Este trabajo examina los cambios que tuvieron lugar en el vocabulario conceptual del mundo jurídico en la Argentina de comienzos del siglo veinte. Impulsados por la percepción de la nueva «cuestión social», los juristas argentinos modificaron concepciones tradicionales en torno a la responsabilidad individual, la propiedad privada, los contratos particulares, y las facultades del Estado para regularlos. Se analizan tanto el impacto de la circulación transnacional de conocimiento social como el contexto institucional local que facilitaba dicha circulación, como elementos determinantes de esos cambios, vistos como anteriores a los procesos politicos de los años treinta y cuarenta, que han sido tradicionalmente asociados a la renovación de las relaciones entre estado y sociedad.

Palabras Clave: Cuestión social; Reforma social; Derecho civil; Legislación y jurisprudencia; Historia del derecho; Argentina.

En abril de 1922 el juez de la Corte Suprema de Justicia Antonio Bermejo firmaba su disidencia respecto al fallo mayoritario que declaraba la constitucionalidad de una reciente ley del Congreso Nacional que congelaba el precio de los alquileres. Entre los argumentos en los que fundamentaba esa disidencia, Bermejo recordaba las prevenciones que Juan Bautista Alberdi, escribiendo a mediados del siglo XIX, había dejado sobre los peligros que podían significar para la vigencia de la Constitución los poderes regulatorios del estado. Lo que se ha dado en llamar «espíritu nuevo», sostenía el juez disidente, atribuye al estado «la dirección providencial de la actividad económica de los habitantes de la Nación». Bermejo recordaba que, casi dos décadas antes, la Corte (que 
él integraba) se había expresado de manera enérgica sobre esos peligros, que ahora parecían ser ignorados. De concederse esos poderes regulatorios, había sostenido la Corte en 1903, «la vida económica de la Nación con las libertades que la fomentan, quedaría confiscada en manos de legislaturas o congresos que usurparían por ingeniosos reglamentos todos los derechos individuales hasta caer en un comunismo de estado, en que los gobiernos serían los regentes de la industria y del comercio y los árbitros del capital y de la industria privada» ${ }^{1}$. ¿Qué cambios habían hecho posible el arraigo de ese «espíritu nuevo» que expandía notablemente las fronteras de la acción estatal frente a los nuevos problemas económicos y sociales?

Desde mediados del siglo XIX, el mundo occidental registró sucesivas oleadas de cambio conceptual y profundas transformaciones institucionales, expresadas también en el pensamiento jurídico. La globalización del pensamiento jurídico, señaló Duncan Kennedy, produjo, entre 1850 y 1914, el ascenso del «pensamiento jurídico clásico»; y luego, su gradual reemplazo por el ascenso del pensamiento jurídico con orientación «social» entre 1900 y la segunda mitad del siglo veinte. La expansión del pensamiento jurídico clásico coincidió con la difusión del liberalismo como cuerpo de ideas, y se encarnó en una estricta separación entre el derecho y la política, imponiendo una concepción formalista del derecho y una clara distinción entre el derecho público y el derecho privado, de contenido fuertemente individualista. En cierto modo, esos mismos rasgos alimentarían la reacción siguiente. En esta segunda globalización, comenzó a criticarse el carácter exageradamente formalista del pensamiento jurídico clásico, así como sus contenidos individualistas. Estas nuevas tendencias tomarían como lema de la segunda globalización del pensamiento jurídico a «lo social», una abstracción que cumplió en este período un papel parecido al que la «voluntad» o los «derechos» habían cumplido durante el auge del pensamiento jurídico clásico, y que conduciría a una verdadera «crisis de la ortodoxia jurídica» ${ }^{2}$.

Esta segunda ola de globalización del pensamiento jurídico, basada en ese ascenso de «lo social», coincidió en el tiempo con la emergencia o profundización de la llamada «cuestión social». En la mayor parte de las sociedades occidentales esta convergencia impulsó el desarrollo de nuevas capacidades estatales y el surgimiento de nuevas formas de «conocimiento social», que se entrecruzaron en procesos de mutuo fortalecimiento: estudios e investigaciones, prácticas administrativas y políticas públicas se orientaron al tratamiento

\footnotetext{
1 «Ercolano c. Lanteri de Renshaw», Fallos de la Corte Suprema de Justicia de la Nación, CXXXVI, 1922: 180. «Hileret y otro c. Provincia de Tucumán», Fallos, XCVIII, 1903: 20.

2 Kennedy, 2006: 19, 37. Horwitz, 1992. Hespanha, 1998. Donzelot, 2007.
} 
de los nuevos fenómenos sociales, y gradualmente estas formas de conocimiento especializado consagrarían a nuevas elites técnicas y administrativas. No siempre estos procesos obedecieron a la cronología de los cambios políticos; frecuentemente respondieron a lógicas de creación y desarrollo con ritmos propios ${ }^{3}$.

En la Argentina de comienzos del siglo veinte, ese proceso de transformación de la ortodoxia jurídica ${ }^{4}$ hacia un nuevo derecho orientado a regular la intervención del estado en los problemas sociales fue el resultado de distintas vertientes, y las dimensiones jurídicas de la cuestión social local ciertamente respondieron a distintos impulsos, pero al igual que en otras sociedades, una serie de cambios conceptuales en el vocabulario jurídico permitirían redefinir la esfera de acción estatal en un proceso que sería profundizado en las décadas siguientes. Como veremos, en buena medida esa redefinición de las funciones del estado en los problemas sociales había quedado fundamentada en el vocabulario conceptual de las disciplinas jurídicas bastante antes de la llegada de los procesos políticos de las décadas del treinta y el cuarenta, a los que usualmente se atribuye la misma.

Un factor clave en el proceso de circulación de las nuevas doctrinas en el país fueron los cambios en las percepciones locales sobre la formación jurídica y el papel de las universidades tanto en el tratamiento de los nuevos problemas sociales como en la provisión de nuevos elencos profesionales para la administración del estado. Es decir, a la par de las orientaciones universalistas de un cuerpo de conocimientos renovados, se percibían formas concretas de adaptación de los mismos en el ámbito nacional, frecuentemente limitadas por características estructurales y materiales particulares, y por los rasgos propios de los mecanismos sociales específicos por los cuales circulaban esos nuevos conocimientos (en este caso las instituciones del campo del derecho local) ${ }^{5}$. Antes de analizar el contenido de los cambios en el pensamiento jurídico, conviene entonces repasar el contexto intelectual en el que los mismos tuvieron lugar.

${ }^{3}$ Rueschmeyer y Skocpol, 1996. Rodgers, 1998. Para los casos de la Argentina y de América Latina en general, véase Neiburg y Plotkin, 2004. Zimmermann, 2005; 2009. Plotkin y Zimmermann, 2012a y 2012b. Sobre el estudio de la «dimensión jurídica» en la historia del estado, véase Lempérière, 2007.

${ }^{4}$ Para la conformación de esa «ortodoxia jurídica» y su presencia en la historia política, económica y social argentina del siglo XIX, véase Adelman, 1999, capítulo 9. Zeberio, 2008. Tau Anzoátegui, 1977; 2007-2008.

${ }^{5}$ Sobre el peso de esos distintos factores en el estudio de la circulación transnacional de conocimiento, véase Charle, Schriewer y Wagner, 2004. 


\section{LA FORMACIÓN JURÍDICA Y LOS NUEVOS PROBLEMAS SOCIALES}

«Nada más irrisorio que oír llamar doctores a los analfabetos patentados que, año tras año, abortan nuestras facultades de Derecho. Porque ellos ni siquiera sospechan la ciencia jurídica. Son simples procuradores con diploma», escribía para el primer Centenario Gabriel Quiroga, el alter ego de Manuel Gálvez. La figura de los «doctores», era ya desde hace por lo menos una década objeto de crítica sostenida. Esa crítica apuntaba en general sobre dos blancos: uno, el profesionalismo estrecho que orientaba a los estudios jurídicos en la Facultad de Derecho y Ciencias Sociales de Buenos Aires; el otro, la brecha existente entre la pobre formación recibida y la prominencia que los graduados alcanzaban en el sistema político argentino y en la administración del estado. Paul Groussac, reseñando las tesis de graduación de la Facultad en La Biblioteca (1897) se irritaba especialmente con ese «verdadero mandarinato que confiere a su poseedor el botón de cristal, habilitándole sin otro título para todas las funciones políticas y administrativas, para todas las magistraturas de la inteligencia [...]. Basta, en efecto, arrojar una mirada a cualquier rama de los poderes constituidos para comprobar que la República Argentina tiene gobierno de doctores». Escribiendo pocos años más tarde, Carlos Octavio Bunge vinculaba la declinación en los saberes jurídicos con la «empleomanía» imperante: «ven los hombres de leyes decaer su ciencia al mismo tiempo que progresa su gremio, y más en nuestra república, por el excesivo parasitismo de Estado» ${ }^{6}$. Los tres observadores enunciaban un lamento reiterado en el cambio de siglo, lamento que apuntaba a los males que aquejaban a la vida intelectual y cultural argentina del cambio de siglo, - el excesivo materialismo, la pérdida de valores elevados, la corrupción política y administrativa-, y sus argumentos, como bien apuntara Oscar Terán, se insertaban además en el enfrentamiento de la naciente «cultura científica» argentina con la tradición de la crítica estético-literaria del proceso modernizador ${ }^{7}$.

Esos debates, que como sabemos tuvieron también su cara universitaria ${ }^{8}$, se expresaron de manera particular en los claustros de la Facultad de Derecho de Buenos Aires. La entrada en vigencia del Código Civil (1871) y su adopción como instrumento de educación jurídica, principalmente por el liderazgo del titular de la cátedra de Derecho Civil, José M. Moreno, consolidó la predominancia de la escuela de la exégesis francesa, que dominaría por décadas

${ }^{6}$ Gálvez, 1910. Groussac, 1897. Bunge, 1913.

7 Terán, 2000. Una contextualización diferente de estas polémicas y su lugar en la historia del derecho argentino en Tau Anzoátegui, 2007: 11-35. Para los antecedentes de esos debates sobre la formación jurídica en el siglo XIX, véase Zimmermann, 1999.

${ }^{8}$ Halperín Donghi, 2002: 97-98. Buchbinder, 2005. Roldán, 1993. 
la formación de abogados. El formalismo jurídico, coincidente con los rasgos generales del pensamiento jurídico clásico, impondría entonces al estudio minucioso del articulado del Código como el ideal de formación jurídica, y postergaría durante mucho tiempo la apertura a métodos alternativos, como la interacción con las nacientes ciencias sociales. Cuando en 1902 Rodolfo Rivarola intentó modificar el programa de derecho civil al hacerse cargo de un curso como profesor suplente, generó un serio conflicto que tras sucesivos intercambios de notas con las autoridades de la Facultad terminó con la separación de Rivarola del curso ${ }^{9}$. Unos años después, Baldomero Llerena haría una enérgica defensa del Código de Vélez, declarándolo en 1910 como «el más científico que se conoce». Para Llerena, la pretensión de restar tiempo al estudio positivo del Código para dedicarlos a «estudios de crítica jurídica y sociológica» era contraproducente y dejaría a los estudiantes sin saber ni uno ni lo otro ${ }^{10}$. Además de esa rigidez metodológica, la sacralización del texto de Vélez reforzaba los argumentos de defensa de los contenidos doctrinarios del código, herederos de la codificación liberal europea ${ }^{11}$.

Sin embargo, un nuevo espíritu de renovación, que aspiraba a transformar los procesos de formación de juristas y abogados, había comenzado a hacerse sentir tras la huelga de estudiantes de 1903, que paralizó la Facultad y que culminaría en propuestas de reformas del plan de estudios. ${ }^{12}$ En la apertura de los cursos de 1906, el Vicedecano Juan M. Garro reconocía que el plan de estudios había quedado "atrás del movimiento científico moderno» y que no permitía formar «además de meros profesionales, hombres de ciencia, que la cultiven sin miras de lucro». Este cultivo de las nuevas ciencias sociales, además, debía orientarse a la solución de los nuevos problemas que enfrentaba el país: la cuestión obrera, los trusts, las sociedades anónimas, el problema vital de la población, la inmigración, el sistema tributario, la política comercial, eran algunos de los tópicos señalados por $\mathrm{Garro}^{13}$. Poco a poco, si

${ }^{9}$ El intercambio de notas entre Rodolfo Rivarola, la Comisión de Enseñanza, el Decano Juan José Montes de Oca y el Rector Basavilbaso, así como las respectivas resoluciones fueron reproducidas en, Rivarola, 1902. Seguramente, la simpatía de Estanislao Zeballos, director de la revista, con la causa renovadora en la Facultad, facilitó la publicación del descargo de Rivarola.

${ }^{10}$ Llerena, 1910: 112-116.

11 Pestalardo, 1914. Bohmer, 2011. Polotto, 2006. Tau Anzoátegui, 1977. Seoane, 1981. Zeberio, 2008. Sobre la escuela de la exégesis en general, Hespanha, 1998: 196-199.

12 Facultad de Derecho y Ciencias Sociales, 1904: 23-26. Véase también Zimmermann, 2010b.

${ }^{13}$ Facultad de Derecho y Ciencias Sociales, 1906: 8-11. Sobre el clima reformista impulsado por la cuestión social en las cátedras de la Facultad de Derecho, véase también Zimmermann, 1995: capítulos 4 y 5. 
bien el formalismo de la exégesis aparecía como la versión predominante del positivismo en la Facultad, también es cierto que el enfoque de las nacientes ciencias sociales argentinas y la necesidad de acercar al derecho al tratamiento de los nuevos problemas acercaba a paso firme otra vertiente del positivismo a la formación jurídica: el conocimiento científico de los nuevos fenómenos sociales y sus causas como elemento imprescindible para entender el fundamento de las normas jurídicas ${ }^{14}$.

Por último, otra vertiente, que alimentaba los reclamos renovadores, se orientaba a la necesidad de mejorar la enseñanza del derecho para garantizar que la Facultad cumpliera adecuadamente su papel como proveedora de hombres aptos para poblar la administración de los poderes del estado. Esta línea de argumentación tenía larga data, dada la predominancia de los abogados en la elite política del período, pero su importancia se incrementó con la reforma del sistema electoral de 1912 y los consecuentes temores en torno a los efectos que la democratización podía producir en el perfil y las capacidades de los llamados a ejercer funciones públicas ${ }^{15}$.

Es en ese contexto de reconfiguración de la formación jurídica hacia el primer Centenario, en el marco de la agudización de los conflictos sociales en el país, en el que el impacto en el plano local de la renovación del pensamiento jurídico transnacional sobre la cuestión social debe ser interpretado.

RENOVACIÓN DE DOCTRINAS JURÍDICAS. LA LEGITIMACIÓN INTERNACIONAL

Desde fines del siglo XIX, el impacto de doctrinas jurídicas transnacionales vinculadas con la cuestión social se hacía sentir en los claustros de la Facultad de Derecho de Buenos Aires y en las publicaciones especializadas. Examinemos brevemente algunas de las innovaciones jurídicas que despertaban estas inquietudes. Probablemente la que ha recibido mayor atención hasta ahora ha sido la revolución que generó la criminología positivista en el derecho penal. El énfasis puesto por esta escuela en el determinismo biológico o social en los orígenes de la conducta criminal transformó las nociones tradicionales de responsabilidad individual y de vinculación entre ley positiva y valoración moral. Es decir, si la criminalidad era originada por factores que estaban más allá del control de los actores individuales, - como su constitución biológica o el ambiente social en el que estaban insertos-, el castigo de esas conductas solo podía fundamentarse en razones de «defensa social»,

\footnotetext{
14 Pestalardo, 1914. Véase también Tau Anzoátegui, 1977; 2007.

15 Zimmermann, 2010a.
} 
no de condena moral, y esto debía ser acompañado por políticas sociales que apuntaran a modificar los factores determinantes de esas conductas como una forma efectiva de prevenir el crimen ${ }^{16}$.

Si bien esta transformación en la noción de responsabilidad como fundamento de la pena tuvo - como sabemos - enormes repercusiones, eran las iniciativas de cambio en instituciones básicas del Derecho Civil y las divergentes interpretaciones sobre la propiedad privada, los contratos o las relaciones laborales las que generaban mayor inquietud. Ya en 1896, en una conferencia de clausura de su Curso de Derecho Civil en la Facultad de Derecho de la Universidad de Buenos Aires, Carlos Rodríguez Larreta pronosticaba sombríamente: «se cierne sobre el derecho civil el peligro de una gran revolución». Los orígenes de esta revolución debían buscarse en «el vínculo que liga al positivismo con la reforma social [...], ambas tendencias están aliadas para demoler esta organización moderna que se ha levantado sobre las bases de la filosofía individualista y liberal», lo que hacía del socialismo «un adversario irreconciliable del derecho civil» ${ }^{17}$.

En la primera década del nuevo siglo, los temores de Rodríguez Larreta parecían empezar a confirmarse. Entre las disertaciones producidas por los flamantes graduados había quien reclamaba para la legislación civil argentina «reformas fundamentales impuestas por las exigencias de la vida moderna», insistiéndose en que «el individualismo reinante en los Códigos tiende a desaparecer». El colectivismo que caracterizaba a la época implicaba «un conjunto de ideas de difícil avenimiento con el concepto individual que ha presidido hasta aquí las relaciones legales». En el terreno práctico, esta evolución apuntaba a la introducción del contrato colectivo de trabajo celebrado por sindicatos profesionales legalmente reconocidos por el estado ${ }^{18}$.

Otra nueva conceptualización de similar importancia estaba teniendo lugar desde fines del siglo diecinueve en la doctrina sobre la responsabilidad patronal por los accidentes de trabajo, tema que generaría una abundante discusión entre juristas. La elaboración de las nociones de «obligación social» y «riesgo profesional» por juristas franceses, como Maurice Hauriou y Raymond Saleilles, y la ley francesa de 1898 sobre responsabilidad patronal basada en el concepto de risques professionels, fueron importantes precedentes para la

16 Zimmermann, 1992; 1995: 127-131. Sobre la historia de la criminalidad y su tratamiento en América Latina, Aguirre y Buffington, 2000. Salvatore, Aguirre y Joseph, 2001. Caimari, 2004

17 Rodríguez Larreta, 1896: 559-583.

18 Lascano, 1909. Ledesma, 1909. Sobre otras iniciativas de legislación laboral, incluyendo el proyecto de Código del Trabajo de Joaquín V. González, de 1904, y la creación del Departamento Nacional del Trabajo en 1907 véase Zimmermann, 1995: capítulos 8 y 9. 
doctrina argentina. El concepto de riesgo profesional significaba que la responsabilidad por accidentes en el lugar de trabajo no debía ser interpretada como el resultado de una falta por parte del empleador o del empleado, sino como consecuencia de la inevitable inseguridad e impredecibilidad de la era industrial. La solución recaería en un sistema de compensación que reconociera responsabilidad sin atribuir falta. Esta doctrina fue adoptada en la Argentina entre 1902 y 1915 por proyectos de legislación, opiniones doctrinales y fallos judiciales. A la par de las cátedras universitarias, los jueces operaron como portadores del nuevo conocimiento social: a través de sus fallos intentaron cubrir la ausencia de legislación «moderna», y canalizar de ese modo el conflicto social por canales institucionales ${ }^{19}$.

\section{León Duguit en Buenos Aires: LA SOCIALIZACión Del Derecho Privado}

Paradójicamente, junto a los reclamos por encontrar conocimientos arraigados en la realidad nacional que caracterizaron a buena parte de la vida intelectual del Centenario, la ya mencionada segunda globalización de saberes jurídicos sentaba las bases de un nuevo paradigma, y nada simbolizó mejor ese avance que las conferencias dadas por el jurista francés León Duguit en su vista a Buenos Aires en 1911. Duguit, profesor en la Facultad de Derecho de la Universidad de Burdeos, era una figura de gran prestigio en ese momento, prestigio que iría en aumento en los años siguientes, hasta convertirse en los años treinta en una de las figuras más reputadas del mundo jurídico. En 1932, el politólogo inglés Harold Laski comparaba la influencia de Duguit sobre su generación con la que Montesquieu había tenido dos siglos antes, al desarrollar «una nueva ciencia del derecho para un mundo nuevo»; y Gastón Jèze, otra figura de renombre internacional, reiteraba su admiración por la «prodigiosa influencia» que su colega ejercía sobre el pensamiento jurídico contemporáneo ${ }^{20}$.

19 Sobre estos desarrollos en la doctrina legal francesa, Harris, 1989: 105-120. Para la evolución de esta doctrina durante el período en Argentina, Zimmermann, 1995: 93-94, 194195; para la actuación de los jueces argentinos como intérpretes de esta nueva doctrina, Schjolden, 2002; 2009.

${ }^{20}$ Laski, 1932: 121-134. Jèze, 1932:135-151. Ese número de los Archives de Philosophie $d u$ droit et de sociologie juridique, estaba enteramente dedicado a Duguit. Las conferencias de Buenos Aires tuvieron como tema la reconfiguración del derecho privado, pero las contribuciones de Duguit provocaron un similar impacto en el derecho público, particularmente a través de su crítica a la noción de soberanía y su remplazo por la de servicio público. Véase 
Las seis conferencias ${ }^{21}$ que Duguit dictó en la Facultad de Derecho conformaron una clara exposición de los principios básicos de esa «nueva ciencia del derecho». Frente a una audiencia que incluía a varios catedráticos locales que compartían su espíritu reformista (entre otros, Ernesto Quesada, Juan Agustín García, Juan José Díaz Arana, José León Suárez, Alejandro Ruzo, y Alfredo Palacios) ${ }^{22}$, Duguit delineó un nuevo método para la ciencia jurídica, un método «realista», que buscaba superar el carácter «metafísico» que el derecho privado había adquirido desde la sanción del Código Napoleón. Esa nueva ciencia jurídica se orientaba a la elaboración de una nueva concepción «social» de los fundamentos del derecho, que dejaba de lado el carácter «individualista» de las instituciones básicas del derecho privado. Así, introducía Duguit sus propuestas:

La declaración de los derechos del hombre, el Código Napoleón y todos los códigos modernos que proceden más o menos de aquellos dos actos, reposan sobre una concepción puramente individualista del derecho. Hoy se está elaborando un sistema jurídico sobre la base de una concepción esencialmente socialista. Es bien entendido que empleo esta palabra porque no tengo otra, que ella no implica en mi pensamiento ninguna adhesión a cualquier partido socialista, que indica solamente la oposición entre un sistema jurídico fundado en la idea del derecho subjetivo del individuo y el fundado en la idea de una regla social que se impone al individuo.

Aquel sistema reposaba en la concepción metafisica del derecho subjetivo. El sistema jurídico de los pueblos modernos tiende a establecerse sobre la comprobación del hecho de función social, imponiéndose a los individuos y a los grupos. El sistema jurídico del Código Napoleón era de orden metafísico; el nuevo sistema en elaboración es de orden realista ${ }^{23}$.

Los títulos de las conferencias alternaban el anuncio de contenidos que parecían más específicamente técnicos — «La autonomía de la voluntad», «El acto jurídico»o «El contrato y la responsabilidad»- con otros que preanunciaban, incluso para los legos, el carácter innovador del enfoque de Duguit: «El derecho subjetivo y la función social», «La nueva concepción de la libertad», $\mathrm{y}$ «La propiedad como función social». Y, efectivamente, es en

especialmente Duguit, 1901; 1908, 1913. Sobre estas contribuciones de Duguit a la teoría del estado, véase Jones, 1993. Donzelot, 2007.

${ }^{21}$ Las seis conferencias dictadas entre agosto y septiembre de 1911, fueron publicadas ese mismo año en París bajo el título Les transformations générales du droit privé depuis le code Napoléon, y traducidas al español y publicadas en Madrid el año siguiente como Duguit, 1912. Véase también Facultad de Derecho y Ciencias Sociales de la Universidad de Buenos Aires, 1921. La visita de Duguit había sido gestionada por el jurista argentino Antonio Dellepiane en Francia, según La Nación, 23 de agosto de 1911, p. 10.

${ }^{22}$ La lista de personalidades presentes en La Prensa, 27 de agosto de 1911: 7.

${ }^{23}$ Duguit, 1912: 13-14. Facultad de Derecho, 1921: 117. 
estas últimas —en las que la influencia de Durkheim y el solidarismo francés queda explícitamente reconocida - que pueden encontrarse afirmaciones que seguramente generaron polémica en la audiencia. En las mismas, Duguit atacaba cuatro principios constitutivos del sistema civilista clásico, a saber: la libertad individual basada en la idea de autonomía individual; la inviolabilidad del derecho de propiedad; el contrato como acto jurídico por excelencia; y la responsabilidad individual por culpa: «hablar de derechos anteriores a la sociedad es hablar de la nada»; «todo el sistema jurídico fundado en la noción del derecho subjetivo y sobre la concepción individualista se derrumba, arruinado por su misma base»; «la propiedad no es un derecho; es una función social»; «el hombre no tiene el derecho de ser libre; tiene el deber social de obrar, de desenvolver su individualidad y de cumplir su misión social»; «en todas partes la concepción de libertad-función sustituye a la noción de libertad-derecho». Probablemente, la última conferencia, dictada el 13 de septiembre de 1911, sobre la propiedad como función social fue la que más llamativamente reveló la extensión del carácter renovador de la nueva doctrina, según la cual las necesidades económicas de la comunidad primaban sobre la antigua concepción individualista del derecho de propiedad:

De ahí que la propiedad, por decirlo así, se socialice. Esto no significa que llegue a ser colectiva en el sentido de las doctrinas colectivistas; pero significa dos cosas: primeramente, que la propiedad individual deja de ser un derecho del individuo, para convertirse en una función social; y, en segundo lugar, que los casos de afectación de la riqueza a las colectividades, que jurídicamente deben ser protegidos, son cada día más numerosos ${ }^{24}$.

En la Argentina, decía Duguit, la evolución de la propiedad en esta dirección estaba menos avanzada que en Europa. En el país preponderaba todavía lo que él llamaba «la propiedad-especulación», pero eventualmente se alcanzaría la etapa, no muy lejana, de «la propiedad-función», «ya que la evolución de las sociedades, y particularmente de las sociedades latinas que han llegado a un mismo grado de civilización, es semejante».

Vale la pena recordar aquí la centralidad que los debates sobre el carácter de la propiedad privada, sus orígenes y las instancias de regulación sobre la

${ }^{24}$ Duguit, 1912: 142. Crónicas de esta última conferencia y de la despedida de Duguit de la Facultad de Derecho pueden encontrarse en La Nación, La Tribuna, y El Nacional del 14 de septiembre de 1911. En este último, en una columna firmada por «Lorimer», se narraba la despedida hecha en francés por el presidente del Centro de Estudiantes de la Facultad, señor Díaz de Vivar, «ese hijo de Corrientes tan grandilocuente [...]. Era de verse la barba de M. Duguit en rítmico balanceo de placer, oyendo los balbuceos de su idioma, lanzados en el más perfecto acento guarany, que tanto se presta para ello». 
misma tenían en las discusiones sobre la cuestión social, particularmente en la doctrina jurídica francesa que tendría tanto ascendiente sobre Vélez en la redacción del Código Civil, y en las nuevas corrientes que encarnaba el «derecho social» postulado por Duguit. Desde la sanción del Código Napoleón hasta la revolución de 1848, fueron los juristas franceses de la Restauración y de la Monarquía Orleanista quienes desarrollaron la estructura jurídica que consagraba el carácter absoluto de la propiedad privada, y las regulaciones en concordancia sobre la posesión y la prescripción; pero fueron también juristas franceses quienes sentaron las bases para el acercamiento del derecho a la nueva «economía social» que transformaría la manera de entender la propiedad y sentarían las bases de los nuevos enfoques del cambio de siglo hacia la cuestión social ${ }^{25}$.

Examinemos cómo se trataban esas materias en el derecho civil argentino. Esas mismas fuentes doctrinales francesas aparecían en las notas del articulado del Código Civil que había entrado en vigencia en 1871. El Código Napoleón había establecido el derecho de gozar y disponer de las cosas «de la manera más absoluta», en sus artículos 544 y 545, decía Duguit, y lo mismo había afirmado el Código de Vélez, de un modo «todavía más enérgico y más significativo». Los artículos del texto argentino que fijaban las características del dominio sobre las cosas y su carácter exclusivo (artículos 2506 y 2508) eran los elegidos como blanco por Duguit, al igual que el artículo 17 de la Constitución Nacional, que fijaba el carácter «inviolable» de la propiedad. Pero Vélez había ido aún más lejos en el artículo 2513: «es inherente a la propiedad, el derecho de poseer la cosa, de disponer o de servirse de ella, de usarla y gozarla según la voluntad del propietario. Él puede desnaturalizarla, degradarla o destruirla...». Y en la nota al pie de ese artículo, Vélez había ampliado los fundamentos de esa norma: «Es preciso reconocer que siendo la propiedad absoluta, confiere el derecho de destruir la cosa. Toda restricción preventiva tendría más peligros que ventajas. Si el Gobierno se constituye juez del abuso, ha dicho un filósofo, no tardaría en constituirse juez del uso, y toda verdadera idea de propiedad y libertad sería perdida.» En la misma línea, el artículo 2514 sostenía que el ejercicio de esas facultades no podía ser restringido porque tuviera por resultado privar a un tercero de alguna ventaja, comodidad, o placer, o traerle inconvenientes, «con tal que no ataque su derecho de propiedad» ${ }^{26}$.

Y sin embargo, también en el texto de Vélez podían encontrarse las semillas de una interpretación de la propiedad en los términos que Duguit describiría

\footnotetext{
${ }^{25}$ Kelley y G. Smith, 1984: 200-230.

${ }^{26}$ Código Civil de la República Argentina, 1977: 495.
} 
como la «propiedad-función», o, más generalmente, del «derecho social». La nota al artículo 2506 citaba a las Partidas para definir a la propiedad como «poder que home ha en su cosa de facer de ella o en ella lo que quisiere, según Dios é según fuero»; pero aclaraba que otra ley decía: «maguer el home haya poder de facer en lo suyo lo que quisiere, pero débelo facer de manera que non faga daño ni tuerto a otro». La nota de Vélez al artículo 2508 extendía aún más esa interpretación: "cuando establecemos que el dominio es exclusivo, es con la reserva que no existe con ese carácter, sino en los límites y bajo las condiciones determinadas por la ley, por una consideración esencial a la sociedad: el predominio, para el mayor bien de todos y de cada uno, del interés general y colectivo, sobre el interés individual ${ }^{27}$.

Esa misma referencia a la ley de las Partidas citada por Vélez puede verse en el fallo de la Corte Suprema de la Nación en el caso «Saladeristas Santiago, José y Jerónimo Podestá y otros c. Provincia de Buenos Aires», de 1887, fundamentando la constitucionalidad de una ley de la legislatura de la provincia de Buenos Aires ordenando la clausura de los saladeros que echaban sus desperdicios en el Riachuelo. Al año siguiente, en el caso «Elortondo» sobre expropiación de terrenos para la construcción de la Avenida de Mayo, si bien la Corte había señalado la amenaza de «un verdadero socialismo de Estado en que este último sería todo y el ciudadano nada», tanto en el dictamen del procurador Eduardo Costa como en la disidencia del juez Salustiano Zavalía (que criticaba la idea de «la omnipotencia del Congreso, que se presenta como un fantasma a la imaginación asustadiza de los propietarios») podía percibirse el avance de los nuevos criterios. Eduardo Costa sostenía: «el derecho de la colectividad ha ganado en nuestros días lo que ha perdido el privado; es un hecho que no escapa a la penetración del observador menos avisado», y no tenía pruritos en enunciar más detalladamente que:

Mejorar las condiciones de vida, en los grandes centros de población sobre todo, facilitando las comunicaciones, mejorando las habitaciones de los pobres y trabajadores, abaratando las subsistencias, es hoy el primer deber del gobierno de un pueblo civilizado, y este deber no podría ser cumplido bajo el respeto sin límites que se tributaba en otros tiempos al derecho de propiedad ${ }^{28}$.

Como veremos, en los años siguientes estas interpretaciones serían retomadas tanto en el debate parlamentario como en la jurisprudencia para apoyar posiciones que impulsaban un mayor grado de intervención estatal en la regulación de la propiedad privada y las relaciones económicas. Pero las

${ }^{27}$ Ibidem: 492-494.

28 «Saladeristas», Fallos de la Corte Suprema de Justicia de la Nación, 1888: 273-284. «Elortondo», Fallos, 1889: 163-211. La cita de Eduardo Costa en p. 180, énfasis agregado. 
presentaciones de Duguit presentaban un tono de innovación que parecía más atractivo que las reformulaciones que se venían postulando en el plano local.

Además de ser cubierta regularmente por la prensa periódica - que reportaba tanto las conferencias y sus contenidos como las visitas que el ilustre invitado realizaba a la Facultad de Medicina, el Hospital de Clínicas, la maternidad del Hospital San Roque (donde declaró haber encontrado un laboratorio de embriología «único en el mundo») y los frigoríficos La Negra y La Blanca ${ }^{29}$ — la presencia de Duguit en Buenos Aires, y sobre todo la exposición sistemática de sus principios de revisión de las bases del sistema de derecho civil clásico, no podía menos que generar reacciones en el ámbito académico $^{30}$. Tras su partida, fueron apareciendo algunas expresiones de ese impacto. En 1912, Enrique Ruiz Guiñazú sostenía que las ideas de Duguit podían servir de fundamento a una variante de «sindicalismo conservador», dado que el francés se orientaba a la atenuación de la lucha de clases y, en cuanto al derecho público, apuntaba a una reorganización de la estructura del estado en organizaciones descentralizadas que tenían al servicio público como fundamento. De todos modos, concluía Ruiz Guiñazú, Duguit pecaba de ingenuidad al pensar que podía prescindirse de «un elemento superior dirigente y moderador ${ }^{31}$. Unos meses más tarde, en la inauguración de su curso de Economía Política de 1913, dictado en la Facultad de Derecho de Buenos Aires, Ruiz Guiñazú acercaba posiciones al hacer notar que la nueva economía social «no se fía en el libre juego de las leyes naturales para asegurar la felicidad de los hombres»; al mismo tiempo que reconocía que, en cuanto a la evolución de la propiedad, el análisis del marxismo no ofrecía respuestas aceptables: «no se concentran los capitales, sino que se democratiza la propiedad a tal punto que es incalculable la proporción de proletarios convertidos en pequeños burgueses ${ }^{32}$.

Menos optimista en sus apreciaciones fue Carlos Ibarguren, profesor de Derecho Romano, encargado de despedir en nombre del claustro a los gra-

${ }^{29}$ Las visitas a los hospitales y los frigoríficos, en La Razón, 29 de agosto de 1911; El Diario, 30 de agosto de 1911; El Nacional, 12 de septiembre de 1911. Crónicas más detalladas de los contenidos de las conferencias pueden verse en La Nación, 3, 7, 10 y 14 de septiembre de 1911; La Prensa, 7, 10, y 14 de septiembre de 1911.

${ }^{30}$ En 1908, Duguit había anticipado que iba a enfrentar la oposición de «los juristas ortodoxos», que habían sido «nutridos por el romanismo, inclinados a ver en el Digesto, en Pothier y en el Código Napoleón la última palabra de la sabiduría humana». Duguit, (1908) 1921:59.

31 Ruiz Guiñazú, 1912b: 229-242. Para las interpretaciones de Duguit sobre el sindicalismo como base de organización de un futuro estado corporativo véase Logue, 1983: 194-202. Sobre otras propuestas en esa línea durante la Tercera República Francesa, Jones, 1993: 55-84.

32 Ruiz Guiñazú, 1913: 31-40; 1912a: 363-375. 
duados en 1912. Ibarguren parecía retomar las preocupaciones expresadas por Rodríguez Larreta en 1896 ya citadas sobre los peligros que podían significar las transformaciones teóricas en el campo del derecho civil. Ibarguren apuntaba especialmente a «las utopías de los teorizadores», que no estaban apoyadas en una realidad social que las justificara, y sus prevenciones parecían apuntar a las innovaciones que Duguit había planteado pocos meses antes:

El peligro no está en el proletariado que se lanza virilmente a la áspera defensa de sus derechos. Lo veo más arriba: en las utopías de los teorizadores y en muchas innovaciones que el verbo revolucionario diluye con fraseología sentimental. Ellas pueden penetrar en el ánimo de magistrados o de legisladores e iniciar, sin que la presión ni la realidad social lo reclamen, atrevidas reformas que trastornarían ex abrupto el orden existente. La mutación viable de las instituciones no se realiza con raciocinios ni se apresura con abstractas doctrinas; es fenómeno natural que se elabora en hondos períodos. Todo fruto inactual es deleznable a pesar de la ruidosa urdimbre de palabras que la sustente ${ }^{33}$.

En una línea parecida, Carlos Octavio Bunge, en su discurso de incorporación a la Academia de Derecho y Ciencias Sociales de Buenos Aires de ese mismo año, rescataba a la vieja formación «profesionalista» (a la que de todos modos no dejaba de ver como necesitando nuevos parámetros de exigencia y rigor), contra lo que parecía una incontenible ola renovadora de impulso a la incorporación de las nuevas ciencias sociales en la Facultad (y ciertamente la influencia de Durkheim en el pensamiento de Duguit traía permanentemente a colación la necesidad de incorporar el análisis sociológico a la formación jurídica):

Las asignaturas político-sociales no ofrecen muy señalada utilidad sino para los abogados que, sin ejercer la profesión, se dediquen a especulaciones científicas o a funciones gubernativas. Son estos unos pocos, a quienes no pueden sacrificarse los intereses positivos de la mayoría, destinada a vivir de los honorarios que a cada cual proporcione el ejercicio de la profesión.

Para Bunge, la solución residía en restaurar la formación técnica profesional para todos, y relegar «los estudios políticos y sociales» a los cursos de doctorado en la misma Facultad de Derecho, o a los ofrecidos en la Facultad de Filosofía y Letras ${ }^{34}$. Quedaba claro, sin embargo, que además de las preocupaciones por el impacto que sobre el presupuesto nacional podía tener la necesidad de emplear a nuevas camadas de letrados orientados a la función pública, se registraban señales de temor por la orientación que el derecho comenzaba a tomar como instrumento de acción estatal sobre la sociedad.

${ }_{33}^{33}$ Ibarguren, 1912: 353-361. Ver también su libro de memorias, Ibarguren, 1977: 331-333.

${ }^{34}$ Bunge, 1913. 
Los nuevos abogados podían comenzar a ser no solo hombres de gobierno y administración, sino también la vanguardia en la reconfiguración de los límites a esa acción estatal, inaugurando una nueva era de reformas legislativas o interpretaciones judiciales que parecían dar por finalizado el predominio del liberalismo clásico en el pensamiento jurídico argentino.

\section{EL NUEVO DERECHO EN LA LEGISLACIÓN Y LA JURISPRUDENCIA}

Una década más tarde - tras los temblores producidos por la Primera Guerra Mundial, el vislumbrar de la polarización ideológica que comenzaría a dominar el panorama cultural europeo en los años veinte, la profunda crisis económica que afectó al país entre 1913 y 1917, y el recrudecimiento del conflicto obrero en la Semana Trágica de 1919- los cambios en la doctrina y la jurisprudencia locales ya reflejaban el avance sostenido de las nuevas doctrinas. En 1921, celebrando - por encargo de la Facultad- el cincuentenario de la entrada en vigencia del Código de Vélez, uno de los especialistas más reconocidos, Alfredo Colmo, no dudaba en afirmar la necesidad de revisar el texto, y mostraba qué lejos se estaba ahora de las expresiones de admiración por la obra del codificador que habían caracterizado a la opinión dominante años atrás:

A mí no se me ha encargado el panegírico del Código ni de su autor. De consiguiente, no tengo por qué decir si el Código figura entre los mejores del mundo, ni si el doctor Vélez ha sido y es una lumbrera del derecho. [...] Con relación a su época y a las restantes circunstancias — sobre todo la de ser fruto de pocos años de labor y la de ser obra exclusiva de un solo hombre - fue un buen Código y hasta un gran Código, por su métodos, por su riqueza institucional y de principios, por el acierto y la previsión de muchas de sus disposiciones. [...] No vengo, pues, a hacer una apología. [...] La Facultad es una institución científica y no un templo. En todo caso, en su ara no se quema incienso ni se atribuye importancia a las liturgias tan externas y suntuosas de las fórmulas rituales ${ }^{35}$.

${ }^{35}$ Colmo, 1921: 321-338. Colmo encaró su tarea con cierto enojo por lo que consideraba una insuficiente atención al aniversario, lo que en cierto modo era también indicativo de la crisis en la que parecía inmerso el derecho civil: «El cincuentenario del Código Civil no queda dignamente conmemorado con este acto. Debió ser una fiesta intelectual, y apenas si es una ceremonia. Hubo de ser un banquete científico, y gracias si se limita a una pobre conferencia. Mereció ser un hecho, algo estable y duradero, y solo alcanza a la volante fugacidad de un conjunto de palabras. [...] Ahí están, en el mero papel y totalmente incumplidas, las ordenanzas que votara la Facultad para celebrar la conmemoración: un libro de estudios diversos acerca de cada uno de los principales órdenes institucionales del código; una edición modelo del mismo código... Eso habría quedado. Eso habría mostrado en juego del Código en nuestra 
En su análisis de la necesidad de reformas que presentaba el Código, Colmo se detenía en los nuevos problemas sociales y las dificultades para enfrentarlos desde un punto de vista jurídico con la normativa del texto de Vélez. Para el Código, «el derecho industrial y obrero no es, seguramente, uno de sus preferidos.» El Código adolecía de «un individualismo llevado al pináculo», y la noción misma del contrato que dejaba establecida era «rudimentariamente romanista». Las fallas en este frente eran graves ya que, según Colmo, «la sugestión libresca e imitativa no permitió comprender al codificador que en cualquier país, sobre todo en un país nuevo, el trabajo es un elemento vital de desarrollo y auge, y no le dio así pie para sentar ni siquiera los principios básicos de un derecho tan fundamental. Al contrario, todo cuanto se refiera al trabajo más común, al trabajo del obrero, quedó o proscripto en algunos casos, o, lo que es peor, plenamente olvidado en la inmensa mayoría de los supuestos» ${ }^{36}$.

Recordemos que tras los sucesos de la Semana Trágica, entre 1919 y 1921 el presidente Yrigoyen envió al congreso varios proyectos de legislación laboral, culminando con la presentación de un proyecto de Código de Trabajo, que presentaba el nuevo acercamiento a las relaciones laborales, reclamado por Colmo en esos mismos días ${ }^{37}$.

Colmo concluía su análisis con una referencia directa a las enseñanzas de Duguit. Mas allá del tratamiento de la cuestión obrera, era necesario que el Código dejara de ser considerado «una cosa arqueológica», como se lo trataba al momento, y a tal efecto debía incorporarse como principio a «la socialidad, en vez del individualismo, para que los derechos sean una función antes que una potestad ${ }^{38}$.

vida. Eso habría sido el punto de partida para las reformas y mejoras que el Código exige». Idem: Colmo había sido ya crítico de los efectos negativos que la enseñanza «palabrera y memorística» del Código tenía en los estudiantes. Véase Colmo, 1915.

${ }^{36}$ Colmo, 1921: 334, énfasis agregado.

37 Rock, 1977. Falcón, 1996: 75-85. Falcón señala un giro en la política de Yrigoyen tras los acontecimientos de 1919: luego de una primera etapa marcada por un tipo de intervenciones personales en los conflictos, Yrigoyen se habría inclinado por «una actitud más institucional», encarnada en los proyectos legislativos enviados al Congreso entre 1919 y 1921 y orientados a la regulación de las relaciones laborales, que mantenían como inspiración los principios de «armonía social» y «solidaridad» de raigambre krausista. Ibidem: 79.

${ }^{38}$ Colmo, 1921: 337-338, énfasis agregado. El mismo Duguit volvía a reafirmar ese mismo año que ese proceso de transformación en el concepto de propiedad estaba ya bien avanzado: «El individualismo propietarista, tal como lo produjo la Revolución Francesa, de la que es legítimo heredero, está, sin el menor género de duda, en camino de desaparecer. El concepto individualista puro no corresponde ya ni a los hechos ni a las ideas de nuestra época. [...] La propiedad capitalista ya no se entiende hoy como el derecho intangible del titular, sino como una situación que le impone obligaciones [...]». Duguit, 1921: 53. 
Escribiendo en 1926, Juan José Díaz Arana, otro destacado catedrático de la Universidad de Buenos Aires de derecho y economía política, reconocía que para ese entonces ya eran pocos los que preconizaban «el liberalismo más o menos puro, [habiéndose acentuado] entre los juristas que saben vincular el derecho con la economía una tendencia adversa al liberalismo clásico». No era solamente una nueva concepción de la propiedad lo que estaba detrás de esa reacción, sino también el reconocimiento de que las desigualdades económicas limitaban fuertemente el principio de la libertad de contratar: «se reacciona contra el principio de la autonomía de la voluntad en los contratos» ${ }^{39}$.

Esa revisión, que apuntaba a la incorporación de una nueva conceptualización de la propiedad privada y la libertad de contratar, supuestamente iluminadas ahora por su carácter de función social, y que era vista como un elemento clave en el tratamiento de la nueva cuestión social, iba a trascender los ámbitos de los claustros y las publicaciones especializadas para hacer su aparición también en el debate parlamentario y los fallos judiciales.

Al discutirse, también en 1921, en el Congreso Nacional el proyecto de ley de congelamiento de alquileres y la suspensión de los desalojos (eventualmente sancionados como ley 11.157), el diputado socialista Antonio de Tomaso defendía el proyecto, en contra de la opinión de quienes veían la misma como un ataque a los principios constitucionales de defensa de la propiedad. Al hacerlo, no fundamentaba su posición en los principios del socialismo, sino que retomaba el texto del Código, pero rescatando las observaciones ya citadas que el mismo Vélez había ofrecido sobre la regulación de la propiedad con fines sociales:

En su oportunidad mencioné, contestando las objeciones de algunos de los señores diputados, que eso lo había hecho notar en forma expresa el mismo codificador cuando en la nota puesta al artículo 2508, que define al dominio como exclusivo, manifiesta lo siguiente: «cuando establecemos que el dominio es exclusivo, es con la reserva de no aceptarlo con ese carácter sino en los límites determinados por la ley, por una consideración esencial a la sociedad: el predominio, para el mayor bien de todos y de cada uno, de los intereses generales y colectivos sobre el interés individual». Por eso, cada vez que el interés social o colectivo ha exigido una limitación, una reglamentación del derecho de propiedad, se ha realizado ${ }^{40}$.

Y el diputado católico Arturo Bas no dudaba en defender no solo el proyecto sino también la nueva concepción de la propiedad como función social sobre la cual él mismo se fundamentaba:

39 Díaz Arana, 1926: 211-225.

40 Diario de Sesiones de la Cámara de Diputados, 9 de junio de 1921: 480, énfasis agregado. 
La propiedad desempeña una función social, y dentro de la evolución impuesta por las necesidades, su legislación debe también modificarse. Es necesario no equivocarse, porque tarde o temprano esa transformación ha de venir, y los que nos consideramos conservadores - entre los que yo me encuentro en primer término- debemos tener una noción clara de la situación y no pretender encerrarnos en principios absurdos, por lo absoluto [...] las transformaciones evidentes de los conceptos y valores económicos y sociales exigen también una interpretación distinta de los principios absolutos que han regido hasta hoy el derecho de propiedad ${ }^{41}$.

Sancionada la ley, y habiéndose planteado el caso de la inconstitucionalidad de la misma, la Corte Suprema terminó afirmando la validez de los nuevos principios en el fallo «Ercolano» (1922), que había ocasionado la disidencia del juez Bermejo citada al comienzo de este trabajo. La mayoría dejó asentadas señales claras sobre el avance de la regulación de los derechos individuales, que no podían ser considerados en modo alguno como absolutos, a riesgo de promover «una concepción antisocial». En particular, la regulación de precios y tarifas aparecía ahora como una clave para la solución de los nuevos problemas sociales, y se atribuía a ese tipo de medidas el propósito de «librar al público de opresiones o tiranías de orden económico»: «la concurrencia de los dos elementos, interés público intenso y monopolio, plantea un conflicto entre el derecho del particular que pretende usar libremente de su propiedad y el interés de evitar los graves males que podría acarrear a la sociedad el abuso de esa libertad», y ese conflicto se zanjaba para la Corte imponiendo limitaciones a los propietarios ${ }^{42}$.

En 1934, la Corte extendería a la regulación de los créditos hipotecarios el criterio que había sido aplicado en 1922 al congelamiento de los alquileres. Ante un caso que planteaba la inconstitucionalidad de la ley 11.741, que reducía los intereses y prorrogaba los plazos para el pago del capital del préstamo para deudores hipotecarios, la Corte se preguntaba: «¿qué residuo de poder queda aún en los Estados, en relación al efecto de los contratos, para proteger los intereses vitales de la comunidad?». Fundada en un abundante análisis de la jurisprudencia de la Corte de los Estados Unidos (y en particular del fallo de esta última de pocos meses antes en el caso "Home Building \& Loan Association v. Blaisdell», de características parecidas al caso argentino), la respuesta - con la disidencia del juez Roberto Repetto- fue la confirmación del criterio establecido en el caso «Ercolano», ya citado. Ante el temor por las consecuencias sociales de la emergencia económica, la propiedad privada y la vigencia de los contratos particulares debían subordinarse a «los intereses vitales de la comunidad ${ }^{43}$.

\footnotetext{
${ }^{41}$ Ibidem: 485.

42 «Ercolano», Fallos, CXXXVI, 1922.

43 «Avico c. De la Pesa», Fallos, CLXXII, 1934.
} 


\section{Conclusiones}

Podemos ver esa evolución en el pensamiento jurídico argentino y su impacto en los acercamientos a la cuestión social como la ilustración de una hipótesis más general: las fronteras del campo de acción del Estado que definen la intersección entre lo público y lo privado se constituyen y redefinen no solamente a partir de grandes cambios ideológico-políticos, sino también a partir de sucesivos cambios originados en el seno de disciplinas y prácticas específicas ${ }^{44}$. Los gobiernos conservadores de la década del treinta y el peronismo en la década siguiente introducirían grandes novedades en las formas de acercamiento del estado a la cuestión social, tanto en las inspiraciones ideológicas que orientaban la acción política como en el diseño y organización de nuevas instituciones y órganos administrativos ${ }^{45}$. No obstante la innegable discontinuidad que esas innovaciones produjeron, debemos considerar que las mismas tenían lugar en un contexto histórico en el cual una gradual transformación en el vocabulario conceptual jurídico había ido estableciendo nuevos sentidos a la propiedad privada, la autonomía de la voluntad, la responsabilidad individual y la estabilidad de los contratos entre particulares. Sin caer en una concepción ingenua en torno al poder de las doctrinas sobre la realidad ${ }^{46}$, debemos investigar más profundamente las formas en las que esos cambios conceptuales fueron modificando el debate público argentino, y de qué manera esas modificaciones contribuyeron a crear las condiciones de factibilidad de los proyectos políticos que se desenvolvieron en las décadas siguientes.

\section{BibLIOGRAFÍA}

Adelman, Jeremy, Republic of Capital. Buenos Aires and the Legal Transformation of the Atlantic World, Stanford, Stanford University Press, 1999.

Aguirre, Carlos y Buffington, Robert (eds.), Reconstructing Criminality in Latin America, Wilmington, SR Books, 2000.

${ }^{44}$ Plotkin y Zimmermann, 2012b: 10.

45 Sobre la década del treinta véase Gaudio y Pilone, 1983; 1984. Persello, 2011a; 2011 b. Sobre las innovaciones del Estado peronista, Berrotarán, 2004. Campione, 2007. Sobre las relaciones entre el peronismo y la regulación jurídica del mundo del trabajo, Palacio, 2009; y Palacio, en prensa.

${ }^{46}$ Sobre la relación entre cambios conceptuales y cambio político, véase Skinner, 1988. Farr, 1989. 
Berrotarán, Patricia, Del plan a la planificación. El Estado durante la época peronista, Buenos Aires, Imago Mundi, 2004.

Böhmer, Martín, «The Politics of Legal Education», ms, 2011.

Bruno, Paula, Travesías intelectuales de Paul Groussac, Bernal, Universidad Nacional de Qulmes, 2004.

Buchbinder, Pablo, Historia de las Universidades Argentinas, Buenos Aires, Editorial Sudamericana, 2005.

Bunge, Carlos Octavio, «La actual crisis de los estudios jurídicos». Discurso de recepción en la Academia de Derecho y Ciencias Sociales de Buenos Aires, 17 de diciembre de 1912, Buenos Aires, 1913.

Caimari, Lila, Apenas un delincuente. Crimen, castigo y cultura en la Argentina, 1880-1955, Buenos Aires, Siglo XXI Argentina, 2004.

Campione, Daniel, Orígenes estatales del peronismo, Buenos Aires, Miño y Dávila, 2007.

Charle, Christophe, Schriewer, Jürgen y Wagner, Peter (eds.), Transnational Intellectual Networks. Forms of Academic Knowledge and the Search for Cultural Identities, Frankfurt/New York: Campus Verlag, 2004.

Código Civil de la República Argentina (1871), Buenos Aires, Abeledo Perrot, 1977.

Colmo, Alfredo, La cultura jurídica y la Facultad de Derecho, Buenos Aires, 1915.

Colmo, Alfredo, «El Código Civil en su cincuentenario», Revista de Filosofía, VII, 2, 1921: 321-338.

Díaz Arana, Juan José, «La libertad de contratar», Anales de la Facultad de Ciencias Jurídicas y Sociales de la Universidad de La Plata, 1926: 211-225.

Donzelot, Jacques, La invención de lo social. Ensayo sobre la declinación de las pasiones políticas, Buenos Aires, Ediciones Nueva Visión, 2007.

Duguit, Léon, L'Etat, le droit objectif et la loi positive, París, Ancienne Librairie Thorin et fils, 1901.

Duguit, Léon, Le droit social et le droit individual et la transformation de l'État, París, 1908.

Duguit, Léon, Las transformaciones generales del Derecho privado desde el Código Napoleón, Madrid, F. Beltrán, 1912.

Duguit, Léon, Les transformations du droit public, Paris, Librairie Armand Colin, 1913.

Duguit, Léon, La transformación del estado, Madrid, Francisco Beltrán, 1921.

Facultad de Derecho y Ciencias Sociales de la Universidad de Buenos Aires, Proyecto de Reformas de Plan de Estudios (con sus antecedentes), Buenos Aires, Imprenta Didot de Félix Lajouanne, 1904. 
Facultad de Derecho y Ciencias Sociales de la Universidad de Buenos Aires, Apertura de los cursos de 1906, Buenos Aires, 1906.

Facultad de Derecho y Ciencias Sociales de la Universidad de Buenos Aires, Discursos Académicos 1911-1921, Buenos Aires, 1921.

Falcón, Ricardo, «La relación Estado-sindicatos en la política laboral del primer gobierno de Hipólito Yrigoyen», Estudios Sociales, VI, 10, 1996: 75-85.

Fallos de la Corte Suprema de Justicia de la Nación, Argentina, disponibles en http:// www.csjn.gov.ar/microfichas/jsp/consultaTomosFallos.jsp

Farr, James, «Understanding conceptual change politically», T. Ball, J. Farr, y R. Hanson, (eds.), Political innovation and conceptual change, Cambridge, Cambridge University Press, 1989.

Gálvez, Manuel, El diario de Gabriel Quiroga (1910), Buenos Aires, Taurus, 2001.

Gaudio, Ricardo y Pilone, Jorge, «El desarrollo de la negociación colectiva durante la etapa de modernización industrial en la Argentina, 1935-1943», Desarrollo Económico, 90, 1983.

Gaudio y Pilone, «Estado y relaciones laborales en el período previo al surgimiento del peronismo, 1935-1943», Desarrollo Económico, 94, 1984.

Groussac, Paul, «Boletín Bibliográfico. Tesis de la Facultad de Derecho y Ciencias Sociales (1897)», La Biblioteca, V, 1897.

Halperin Donghi, Tulio, Historia de la Universidad de Buenos Aires, Buenos Aires, Eudeba, (segunda edición) 2002.

Harris, Ruth, Murders and Madness. Medicine, Law and Society in the Fin de Siècle, Oxford, Clarendon Press, 1989.

Hespanha, António Manuel, Cultura Jurídica Europea. Síntesis de un milenio, Madrid, Tecnos, 1998.

Horwitz, Morton J., The Transformation of American Law 1870-1960.The Crisis of Legal Orthodoxy, Oxford, Oxford University Press, 1992.

Ibarguren, Carlos, «La sociedad argentina», Atlántida, VII, 1912: 353-361.

Ibarguren, Carlos, La historia que he vivido, Buenos Aires, Ediciones Dictio, 1977.

Jèze, Gaston, «L'influence de León Duguit sur le droit administratif francais», Archives de Philosophie du droit et de sociologie juridique, 1932: 135-151.

Jones, H. S., The French State in Question. Public Law and political argument in the Third Republic, Cambridge, Cambridge University Press, 1993.

Kelley, Donald R., y G. Smith, Bonnie, «What Was Property? Legal Dimensions of the Social Question in France (1789-1848)», Proceedings of the American Philosophical Society, 128, 3, 1984: 200-230. 
Kennedy, Duncan, «Three Globalizations of Law and Legal Thought: 1850-2000», David Trubek y Álvaro Santos, (eds.), The New Law and Economic Development. A Critical Appraisal, Cambridge, Cambridge University Press, 2006.

Lascano, David, Naturaleza Jurídica del Contrato de Trabajo, Tesis presentada para optar al grado de Doctor en Jurisprudencia, Facultad de Derecho y Ciencias Sociales de la Universidad de Buenos Aires, Biblioteca Nacional, Colección Candioti, 1909.

Laski, Harold, «La conception de l'Etat de León Duguit», Archives de Philosophie $d u$ droit et de sociologie juridique, 1932: 121-134.

Ledesma, Ramón F., Naturaleza Jurídica del Contrato de Trabajo, Tesis presentada para optar al grado de Doctor en Jurisprudencia, Facultad de Derecho y Ciencias Sociales de la Universidad de Buenos Aires, Biblioteca Nacional, Colección Candioti, 1909.

Lempérière, Annick, «La historiografía del Estado en Hispanoamérica. Algunas reflexiones», Guillermo Palacios (coord.), Ensayos sobre la historia política de América Latina, siglo XIX, México, El Colegio de México, 2007.

Llerena, Baldomero, «La enseñanza del Derecho Civil», Conferencia de inauguración del curso de Derecho Civil, abril de 1910, Revista de Derecho, Historia y Letras, XXXVI, 1910.

Logue, William, From Philosophy to Sociology. The Evolution of French Liberalism, 1870-1914, Dekalb, Northern Illinois University Press, 1983.

Neiburg, Federico y Plotkin, Mariano (comps.), Intelectuales y expertos. La constitución del conocimiento social en la Argentina, Buenos Aires, Paidós, 2004.

Palacio, Juan Manuel, «De la paz a la discordia: El peronismo y la experiencia del Estado en la provincia de Buenos Aires (1943-1955)», Desarrollo Económico, 194, 2009.

Palacio, Juan Manuel, «La justicia peronista: el caso de las cámaras de arrendamiento y aparcerías rurales (1948-1955)», Anuario IEHS, Tandil, 26, en prensa.

Persello, Ana Virginia, «Representación política y burocracia estatal: las juntas reguladoras de la producción, 1930-1943», http://historiapolitica.com/biblioteca/, 2011a.

Persello, Ana Virginia, «Administración Pública y Partido Gobernante», http://historiapolitica.com/biblioteca/2011b.

Pestalardo, Agustín, Historia de la enseñanza de las ciencias jurídicas y sociales en la Universidad de Buenos Aires, Buenos Aires, Imprenta Alsina, 1914.

Plotkin, Mariano y Zimmermann, Eduardo (comps.), Los saberes del estado, Buenos Aires, Edhasa, 2012a. 
Plotkin, Mariano y Zimmermann, Eduardo (comps.), Las prácticas del estado. Política, sociedad y elites estatales en la Argentina del siglo XX, Buenos Aires, Edhasa, 2012b.

Polotto, $\mathrm{M}^{\mathrm{a}}$ Rosario, «Hacia una nueva experiencia del Derecho. El debate en torno a la enseñanza práctica del derecho en la Universidad de Buenos Aires a comienzos del siglo XX», Revista de Historia del Derecho, 34 (2006).

Rivarola, Rodolfo, «Cuestiones universitarias. El caso de la Facultad de Derecho», Revista de Derecho, Historia y Letras (1902): 5-28.

Rock, David, El radicalismo argentino, 1890-1930, Buenos Aires, Amorrortu editores, 1977.

Rodgers, Daniel T., Atlantic Crossings. Social Politics in a Progressive Age, Cambridge, Mass., The Belknap Press of Harvard University Press, 1998.

Rodríguez Larreta, Carlos, «El socialismo y el derecho civil», La Biblioteca, IV (1896).

Roldán, Darío, Joaquín V. González, a propósito del pensamiento político-liberal (1880-1920), Buenos Aires, Centro Editor de América Latina, 1993.

Rueschmeyer, Dieter, y Skocpol, Theda (eds.), States, Social Knowledge, and the Origins of Modern Social Policies, Princeton, Princeton University Press, 1996.

Ruiz Guiñazú, Enrique, «Interpretación económica de la historia. Teoría del materialismo histórico. (Apuntes)», Atlántida, VI (1912a): 363-375.

Ruiz Guiñázú, «Sindicalismo revolucionario, reformista y conservador», Atlántida, VII (1912b): 229-242.

Ruiz Guiñazú, «La Economía Política y la cuestión social. Conferencia inaugural del Curso de Economía Política en la Facultad de Derecho, Atlántida, X (1913): 31-40.

Salvatore, Ricardo D., Aguirre, Carlos y Joseph, Gilbert M. (eds.), Crime and Punishment in Latin America, Durham, Duke University Press, 2001.

Schjolden, Line, Suing for Justice: Labor and the Courts in Argentina, 1900-1943, tesis doctoral, University of California, Berkeley, 2002.

Schjolden, Line, «Sentencing the Social Question: Court-Made Labour Law in Cases of Occupational Accidents in Argentina, 1900-1915», Journal of Latin American Studies, 41/1 (2009).

Seoane, María Isabel, La enseñanza del derecho en la Argentina. Desde sus orígenes hasta la primera década del siglo XX, Buenos Aires, Editorial Perrot, 1981.

Skinner, Quentin, «Some problems in the analysis of political thought and action», James Tully (ed.), Meaning \& Context. Quentin Skinner and his Critics, Cambridge, Polity Press, 1988. 
Tau Anzoátegui, Víctor, Las ideas jurídicas en la Argentina (siglos XIX-XX), Buenos Aires, Editorial Perrot, 1977.

Tau Anzoátegui, Víctor, Antología del Pensamiento Jurídico Argentino (1901-1945), Buenos Aires, Instituto de Investigaciones de Historia del Derecho, 2007-2008.

Terán, Oscar, Vida intelectual en el Buenos Aires fin-de-siglo (1880-1910). Derivas de la «cultura científica», Buenos Aires, Fondo de Cultura Económica, 2000.

Zeberio, Blanca, «Los derechos civiles en la transición. Controversias jurídicas y proyectos políticos», Marta Bonaudo, Andrea Reguera y Blanca Zeberio (coords.), Las escalas de la historia comparada. Tomo I: Dinámicas sociales, poderes politicos y sistemas jurídicos, Buenos Aires, Miño y Dávila, 2008.

Zimmermann, Eduardo, «Racial Ideas and Social Reform. Argentina, 1890-1916», Hispanic American Historical Review, 72/1 (1992).

Zimmermann, Eduardo, Los liberales reformistas. La cuestión social en la Argentina, Buenos Aires, Editorial Sudamericana/Universidad de San Andrés, 1995.

Zimmermann, Eduardo, «Libéralisme et sciences sociales en Argentine á la fin du dix-neuviéme siécle: des Lumières á la nouvelle 'connaisance sociale'», Darío Roldán, La question libérale en Argentine au 19ème siècle (Le libéralisme argentin en héritage), París, ALHIM, 2005.

Zimmermann, Eduardo, "The education of lawyers and judges in Argentina's Organización Nacional (1860-1880)», E. Zimmermann (ed.), Judicial Institutions in Nineteenth Century Latin America, Londres: Institute of Latin American Studies, Universidad de Londres, 1999.

Zimmermann, Eduardo, «Transformaciones del Estado en América Latina, 1870-1930, Enrique Ayala Mora y Eduardo Posada-Carbó (comps.), Los proyectos nacionales latinoamericanos: sus instrumentos y articulación, Historia General de América Latina, VII, Paris, UNESCO, 2009.

Zimmermann, Eduardo, «Elites técnicas estatales: abogados y juristas», Mariano Plotkin (ed.), Dossier Saberes y Estado, Boletín Bibliográfico Electrónico del Programa Buenos Aires de Historia Política, 6, 2010a.

Zimmermann, Eduardo, «Abogados, científicos y estadistas. Debates sobre la enseñanza jurídica en la Argentina del primer Centenario», Ciencia Hoy, 20/119 (2010b).

Fecha de recepción: 8/10/12

Fecha de aceptación: 15/1/13 


\section{«A New Spirit»: the Social Question and Law in Argentina (1890-1930)}

This article examines changes in the conceptual vocabulary of early twentieth century Argentine legal world. Inspired by their perception of the novel «social question», Argentine jurists modified traditional views on individual responsibility, private property, contracts, and the extent of the regulatory powers of the state. Transnational circulation of social knowledge and local institutional conditions are seen as crucial elements shaping said conceptual changes. In turn, these are seen as preceding the political movements of the 1930s and 1940s, commonly considered the main factors in the transformation of state-society relations.

KEY-worDS: Social Question; Social Reform; Civil Law; Legislation and Jurisprudence; Legal History; Argentina. 